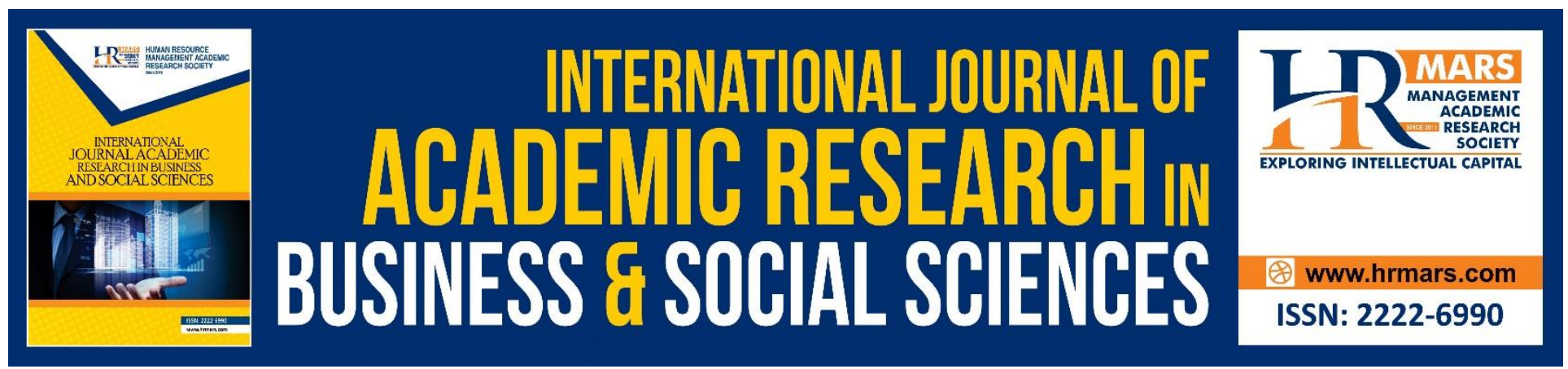

\title{
Integrated Power Training Mode in Soccer: Merging Complex Training with Cluster Set
}

\author{
Adib Jusoh, Asmadi Ishak, James, J. Tufano
}

To Link this Article: http://dx.doi.org/10.6007/IJARBSS/v9-i1/5783

DOI: $10.6007 /$ IJARBSS/v9-i1/5783

Received: 27 Dec 2018, Revised: 11 Jan 2019, Accepted: 27 Jan 2019

Published Online: 07 Feb 2019

In-Text Citation: (Jusoh, Ishak, \& James, 2019)

To Cite this Article: Jusoh, A., Ishak, A., \& James, J. T. (2019). Integrated Power Training Mode in Soccer: Merging Complex Training with Cluster Set. International Journal Academic Research Business and Social Sciences, 9(1), 1192-1202.

Copyright: (C) 2019 The Author(s)

Published by Human Resource Management Academic Research Society (www.hrmars.com)

This article is published under the Creative Commons Attribution (CC BY 4.0) license. Anyone may reproduce, distribute, translate and create derivative works of this article (for both commercial and non-commercial purposes), subject to full attribution to the original publication and authors. The full terms of this license may be seen at: http://creativecommons.org/licences/by/4.0/legalcode

Vol. 9, No. 1, 2019, Pg. 1192 - 1202

http://hrmars.com/index.php/pages/detail/IJARBSS

JOURNAL HOMEPAGE

Full Terms \& Conditions of access and use can be found at http://hrmars.com/index.php/pages/detail/publication-ethics 


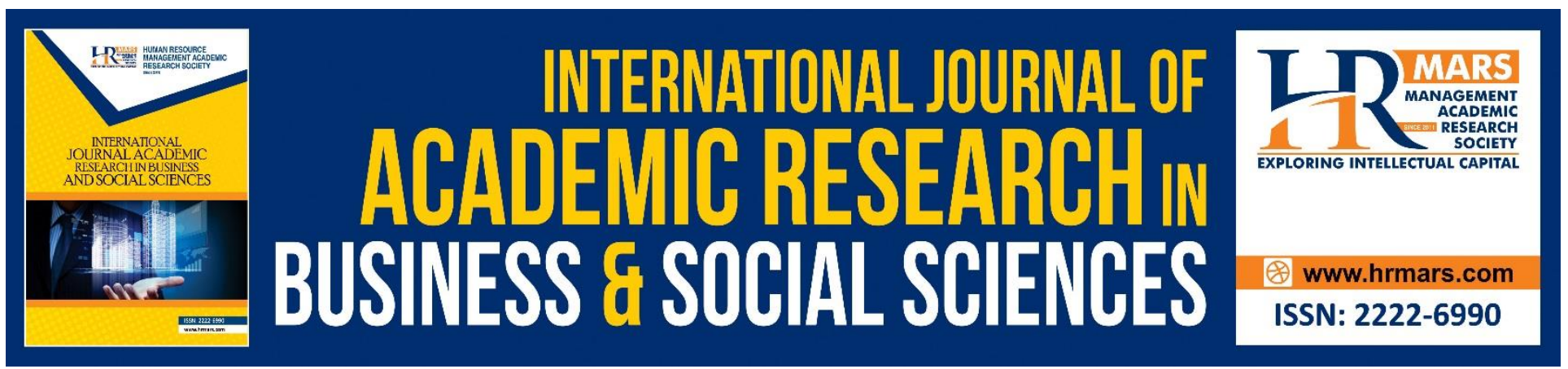

\title{
Integrated Power Training Mode in Soccer: Merging Complex Training with Cluster Set
}

\author{
Adib Jusoh ${ }^{1}$ Asmadi Ishak ${ }^{2}$ James, J. Tufano ${ }^{3}$ \\ ${ }^{1}$ SMK Seri Londang, Gelung Pepuyu Perak, Malaysia \\ 1,2Universiti Pendidikan Sultan Idris, Tg Malim Perak, Malaysia \\ ${ }^{3}$ Charles University, Prague, Czech Republic \\ ${ }^{1}$ seismoziey@yahoo.com
}

\begin{abstract}
Power is one of the most important physical components to excel in modern soccer. Hence, finding the most efficient mode of power training is vital. This article aim is therefore, to propose an idea about a power training mode that might resulted with better power performance in soccer. Traditionally, resistance training and plyometrics will be the choice to be used by the trainers to improve power qualities. However, recent studies on power training had proven that complex training; a combination of resistance training and plyometrics, is a beneficial power training mode. In this article, discussion on power training modes is ultimately resumed by an unexplored research gap; cluster set (CS) application during a complex training. By utilizing the cluster set (CS) during a complex training, a better results of power training might occur.
\end{abstract}

Keywords: Complex Training, Cluster Set, Conditioning, Soccer, Power

\section{Complex Training as a Power Training Mode in Soccer}

According to Fédération Internationale de Football Association (Fédération Internationale de Football Association, 2016), power (strength-speed) and speed are the most important physical capacities and even decisive in modern soccer. The relationship between maximal strength and power has also been recognized as a key contributor to soccer performance (Manson, 2013). This relationship had been revealed by an earlier study findings on a strong correlation, between maximal strength in half squats with sprint performance and jumping height, among elite Norwegian club soccer players (Wisløff, Castagna, Helgerud, Jones, \& Hoff, 2004).

Being mentioned as one of the most important factors in soccer, power performance can be developed via a lot of training form. Resistance, plyometrics (Thomas et al., 2009), combined strength and power training (Faude, Roth, Giovine, Zahner, \& Donath, 2013) and the soccer match itself (Morgans, Di Michele, \& Drust, 2018) have been accredited as a modes of power training. 
Lately a hybrid method where resistance and plyometrics training are completed in one session; namely complex training, has become a norm in power training for all sports including soccer. This intervention has produced positive effects on vertical jump in team-sport athletes and concluded as a suitable option to include in the season planning (Freitas et al., 2017; Argus et al., 2012). In another study, de Villarreal et al. (2013) has proven that combining resistance and plyometrics training in a session has improved strength and speed; both are determinants of power, although it is questionable since volume for all training groups are not equal.

Chen, Lo, Wang, Yu, and Peng (2017) has not recommended complex training in a team setting because some athletes decreased their performance, while others showed improvement. However the statement is still due to further confirmation as this is the first study concerning on the issue and only 10 subjects involved, thus inadequate to be a strong generalization base. Complex training also has been hailed for its time saving nature (Tredrea, 2017). Even more, mobility and/or stability drills during the interphases interval of complex training, has been suggested as an option (Lim \& Barley, 2016). It is important though to bear in mind that all those complex training advantages are dependent on the training status of the individuals, exercise selection and the recovery intervals (Scott, Ditroilo, \& Marshall, 2017). These in fact has added to the rationales for soccer conditioning practitioners to manipulate the rest interval while controlling the training status and exercise selection factors.

Complex training has also been found superior than traditional training in power enhancement (Talpey, Young, \& Saunders, 2016). Enhanced muscle explosiveness after being provoked by heavy resistance, is the logic behind the complex training idea. Resistance training with maximum or near maximum resistance may increase synchronization of motor unit recruitment; believed to provide less contact time and achieve greater maximum height, and ultimately magnifying the effect of the stretch-shortening cycle (SSC) during the subsequent plyometric phase (Ebben, et al., 2000). It has also been found that repeated exposure is needed to gain benefit from complex training (Comyns, Harrison, \& Hennessy, 2010). Agreeing with all the above mentioned benefit whether in soccer or other sports as well, this paper is written with the main purpose to share and discuss the writer's opinion on how can we improve complex training to a further extent.

\section{Cluster sets to optimize the training effects}

In order to optimize the performance outcome of any training including the complex training, variables such as number of repetition, training load, type of exercise, number of set and rest period can be manipulated (Tufano et al., 2016; Bompa \& Haff, 2009). Among those stated variables, rest period within a set is one of the most critical part to ensure that athletes can perform at the maximum level (Tufano et al., 2017). One method to utilize the rest period within a set is the cluster set (CS) configuration. CS training set is completed with IRR, meanwhile traditional set (TS) is performed in sequence without it (Tufano et al., 2016; Boullosa et al., 2013; Haff et al., 2003).

The IRR implementation within a CS is based on the understanding of the recovery - adaptation principles. Recovery is a process of regaining the lost or bouncing an athlete's performance back to where it was. Adaptation deals with the long-term alterations caused by a specific training program. Hence, it has been suggested to the coaches and physical trainers to use the recovery-adaptation term (Sands, Apostolopoulos, Kavanaugh, \& Stone, 2016). Via the cluster set (CS) recovery-adaptation 
INTERNATIONAL JOURNAL OF ACADEMIC RESEARCH IN BUSINESS AND SOCIAL SCIENCES Vol. 9, No. 1, Jan, 2019, E-ISSN: 2222-6990 @ 2019 HRMARS

can actually being promoted not only after the training, but also during the training itself. CS can be done by altering the structure of individual sets in the training (Tufano, Brown, et al., 2016).

\section{Cluster Set on Resistance Training}

The first indication of a cluster set (CS) usage in a resistance training has been recognized in a documents on American football off season training (Roll \& Omer, 1987). Then it started to receive attention among the practitioners. Haff et al. (2003) have examined 3 types of clean pull structures including the CS for two of them and has concluded that CS structure is a better choice for the resistance training.

By using the same relative intensity across the various set structures for the duration of the training program, it is possible that implementing CS structures using the same load as TS may have resulted in a decrease in perceived effort during the CS training sessions, as seen in previous studies (Hardee et al., 2012; Iglesias-Soler et al., 2016; Mayo, Iglesias-Soler, \& Del-Olmo, 2014). Theoretically, increased resistance load use might be possible, allowed by the decreased perceived effort thus resulting higher stimulus for the physiological adaptations that underpin the development of muscular strength (Tufano et al., 2016). Yet, the author of this study did not use the advantage. Since no data were reported on the rate of perceived effort (RPE), and training loads were constant in this study (Hardee et al., 2012), further research is warranted to determine if CS can allow for an increased training load while producing a similar RPE as in TS (Tufano et al., 2016).

Another findings has suggested that CS protocols may not be ideal compared to TS when both groups use the same training loads, volume and total rest time (Hardee et al., 2012; Iglesias-Soler et al., 2016; Mayo et al., 2014). It is possible if the CS group experienced less fatigue, subjects may have been able to tolerate greater training loads, leading to greater strength increase when compared with TS. Meanwhile, Oliver et al., (2013) investigated the effect of CS and TS during a hypertrophy oriented training program. Both group trained with equal total rest time. After 12 weeks, both groups improved bench press, back squat and vertical jump power output, but contradicted with the previous findings, the CS group experienced greater increases in bench press and vertical jump power output compared with TS. Indeed, these contradictions in literature provide gaps in the discipline, and eventually might prompt future researchers to propose a study with an advantage to support any parties, regardless of the findings to be made.

Iglesias-Soler et al. (2016) investigated the effects of a TS and CS protocol over a 5 week period using unilateral knee extensions. Result had shown that TS produced slower mean propulsive velocities ( 0.48 vs $0.54 \mathrm{~m} / \mathrm{s})$ and greater RPE ( 8.3 vs 6.6) than CS, respectively after five weeks of training. However subjects in both the CS and TS group experienced an equal increase in isometric strength, dynamic 1RM, mean propulsive power, and total work. These evidence indicate that in university students of both genders, unilateral knee extension protocol after 5 weeks of CS intervention felt easier but resulted in similar increases in strength and power output compared with TS within the equal training period.

To date, some scholars have reported that strength gains in CS set structure are lower than TS (Hansen, Cronin, Pickering, \& Newton, 2011; Lawton et al., 2004) with only one study providing evidence that CS structures produce superior strength gains (Oliver et al., 2013) and one study showing similar increases in strength for both CS and TS set structure (Iglesias-Soler et al., 2016). At 
first glance, CS structures seems to have a limited application to develop strength. However, it is important to determine why TS resulted in greater strength development compared with CS training in these instances. Within studies that investigate CS, there are two common characteristic, the equalization of the total rest time for both set structure and the lack of training load variation and systematic progression between the CS and TS set structures (Hansen et al., 2011; Lawton et al., 2004). The equalization of training loads between groups is a sound specific method but with the same intensities it is likely that the TS group will experience greater acute fatigue, a greater compensatory response, and possibly greater increase in strength. Therefore, reforming the training strategy where the rest is not going to be equal between CS and TS, and the load will be adjusted to a percentage of a new $100 \% 1$ RM, after 3 weeks of training.

The implementation of different CS configurations has also been found to be effective in reducing the mechanical (velocity loss) and metabolic (blood lactate concentration) measures of fatigue compared to TS while using a 10RM load (García-Ramos et al., 2017). Furthermore, different types of CS protocols can result in pro-anabolic physiological responses to resistance training, and shorter but more frequent sets may allow kinetics and kinematics to remain more constant (Tufano, et al., 2017). Referring to these evidences, the writers had come out with a postulate that the plyometrics phase of the complex training will benefit from the increased preparedness in the resistance phase.

Through the ability to alleviate fatigue, CS has also been proven to acutely decrease cardiovascular stress (Tufano et al., 2016) beside maintaining velocity and power (Tufano et al., 2016) during resistance training. An IRR as short as 6 seconds has been reported to be sufficient enough to induce partial recovery, and could therefore improve muscle power output (García-Ramos et al., 2016). However Tufano et al., (2017) has resolved that the ability to maintain the velocity and power is not due to the CS application, instead more to the type of CS structure. Arguments on this matter once again has warranted a further investigations to clarify the unsettled issue.

\section{Cluster set on plyometrics training}

Another form of power training is the plyometrics training. Effort by the previous researchers to gain extra benefit this training has also included the cluster set (CS) implementation. In a study done by Aminaei et al., (2017), the results indicated both CS and TS plyometric training program seems to improve physical fitness elements at the same levels.

Asadi and Ramirez-Campillo (2016) have earlier investigated the effects of TS and CS plyometric training in college aged students for 6 weeks. After completing the training, increased countermovement jump height, standing long jump distance, and decreased test and 20 and 40m sprint times were present for both TS and CS group. Although there were no significant interactions between groups, the effect size were greater in the CS group for countermovement jump height, long jump distance, and t test time, whereas the effect size were greater for the TS group for 20 and $40 \mathrm{~m}$ sprint times. Therefore, this useful evidence is one of the reason for the writers to support the implementation of CS and plyometrics as a phase of a complex training. In another study result has demonstrated that CS, allow for a greater maintenance of power, take off velocity, and jump height compared to a TS when performing repeated body weight plyometric squat jumps (Moreno, Brown, Coburn, \& Judelson, 2014). Lack of training data precludes definitive recommendations; however, 
INTERNATIONAL JOURNAL OF ACADEMIC RESEARCH IN BUSINESS AND SOCIAL SCIENCES

Vol. 9, No. 1, Jan, 2019, E-ISSN: 2222-6990 @ 2019 HRMARS

based on this data, coaches should have their athletes perform 2-5 jumps with 27-45 seconds rest, respectively. To date, extensive literature search has only found these three CS studies involved plyometrics. This incompleteness has indeed providing a gap to be fulfilled.

\section{Cluster set on complex training}

After an extensive search on previous literature no evidence has been found regarding to the usage of a complete cluster set (CS) in a complex training. In a study conducted by Boullosa et al., (2013), protocol of countermovement jump height was measured before and 1,3,6,9 and 12 minutes after squats with 5RM load for both TS and CS group bad been used. The result had shown that vertical jump post activation potential occurred after 1 minute using the partial CS compared with 9 minutes using TS. However, in this study, the IRR has been applied only during the resistance phase, not in both resistance and plyometrics phases.

Three years later, Treeraj, Kamutsri, Lawsirirat, and Intiraporn, (2016) have also added the IRR of the resistance phase for one of the training groups, while trying to determine the most relevant form of complex training that can provide similar to a soccer game's stimulation. It has been resulted with the partial CS group has been identified to be the most relevant group. Earlier occurrence of post activation potential after the resistance phase with IRR in these stated researches means earlier preparedness to perform subsequent plyometrics drills. Theoretically the effect may be enhanced if the IRR is to be included during plyometrics phase of a complex training. This premise abides to the fitness-fatigue theory, thus resulted to suggestions of a long term positive accumulated increase in performance, if the training is continued for a longer term. Then only the supercompensation theory will make sense. Accordingly, we suggested for future study that the IRR can implemented on both of the resistance and plyometrics phases of a complex training.

\section{Conclusion}

CS has been tried to several training methods, including the resistance training, plyometrics training and resistance phase of a complex training. However it has not been tried on both of the complex training phases. Moreover, scant research on CS application using complex training to develop power for soccer players led to incompleteness in literature. Fulfilling this significant gap will contribute to the knowledge expanding and be beneficial for the soccer practitioners as well as in other sports. Without adequate studies on this matter, using of CS in a complex training to improve power related abilities among soccer practitioners is just an intuitive guess work, not a scientifically proven method as it should be. Accordingly, given all the limitations in the literature, attempt to investigate the effects of CS compared to the TS within a complex training regime to improve power related components in soccer is clearly warranted. 
Figures and tables

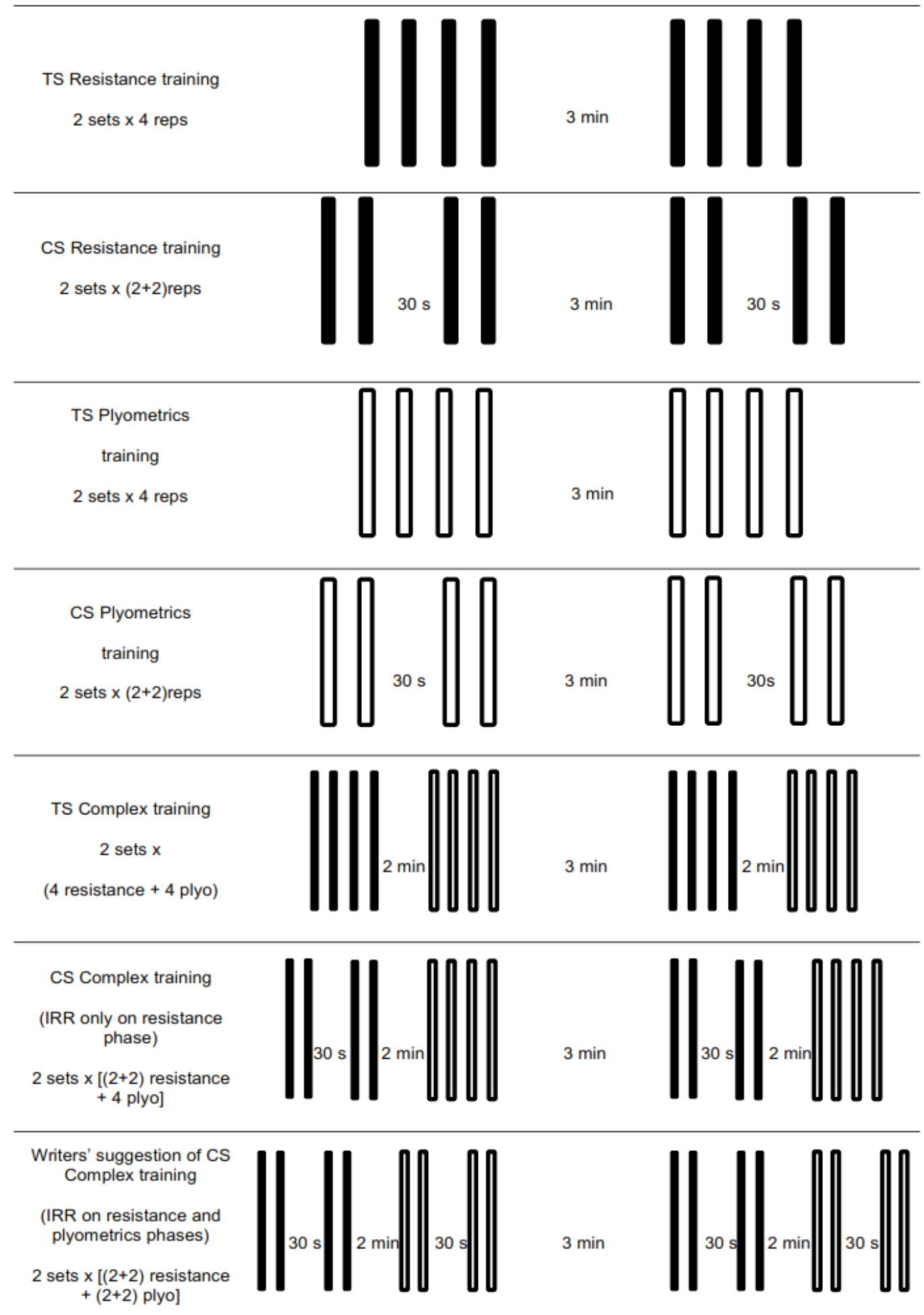

Figure 1.Schematic differences between CS and TS set structures (Tufano et al., 2017) 
INTERNATIONAL JOURNAL OF ACADEMIC RESEARCH IN BUSINESS AND SOCIAL SCIENCES

Vol. 9, No. 1, Jan, 2019, E-ISSN: 2222-6990 @ 2019 HRMARS

\section{Corresponding Author}

Asmadi Ishak

Faculty of Sports Science and Coaching

Universiti Pendidikan Sultan Idris

Tg Malim

Malaysia

Email: asmadi@fsskj.upsi.edu.my

\section{References}

Aminaei, M., Yazdani, S., \& Amirseifadini, M. (2017). International journal of applied exercise physiology. International Journal of Applied Exercise Physiology, 6(2), 34-44. Retrieved from http://www.ijaep.com/index.php/IJAE/article/view/142

Argus, C. K., Gill, N. D., Keogh, J. W. L., McGuigan, M. R., \& Hopkins, W. G. (2012). Effects of two contrast training programs on jump performance in rugby union players during a competition phase. International Journal of Sports Physiology and Performance, 7(1), 68-75. https://doi.org/10.1123/ijspp.7.1.68

Bompa, T. O., \& Haff, G. (2009). Periodization : theory and methodology of training. Champaign, IL: Human Kinetics.

Boullosa, D. A., Abreu, L., Beltrame, L. G. N., \& Behm, D. G. (2013). The acute effect of different half squat set configuration on jump potentiation. Journal of Strength \& Conditioning Research, 27(8), 2059-2066.

Chen, Z.-R., Lo, S.-L., Wang, M.-H., Yu, C.-F., \& Peng, H.-T. (2017). Can Different Complex Training Improve the Individual Phenomenon of Post-Activation Potentiation? Journal of Human Kinetics, 56(1), 167-175. https://doi.org/10.1515/hukin-2017-0034

Comyns, T. M., Harrison, A. J., \& Hennessy, L. K. (2010). Effect of squatting on sprinting performance and repeated exposure to complex training in male rugby players. Journal of Strength and Conditioning Research, 24(3), 610-618. https://doi.org/10.1519/JSC.0b013e3181c7c3fc

Ebben, W. P., Jensen, R. L., \& Blackard, D. O. (2000). Electromyographic and Kinetic Analysis of Complex Training Variables. The Journal of Strength and Conditioning Research, 14(4), 451. https://doi.org/10.1519/1533-4287(2000)014<0451:EAKAOC>2.0.CO;2

Faude, O., Roth, R., Giovine, D. Di, Zahner, L., \& Donath, L. (2013). Combined strength and power training in high-level amateur football during the competitive season: A randomised-controlled trial. Journal of Sports Sciences, 31(13). https://doi.org/10.1080/02640414.2013.796065

Fédération Internationale de Football Association. (2016). Youth football - Training manual.

Freitas, T. T., Martinez-Rodriguez, A., Calleja-González, J., \& Alcaraz, P. E. (2017). Short-term adaptations following Complex Training in team-sports: A meta-analysis. PloS One, 12(6), e0180223. https://doi.org/10.1371/journal.pone.0180223

García-Ramos, A., González-Hernández, J. M., Baños-Pelegrín, E., Castaño-Zambudio, A., CapeloRamírez, F., Boullosa, D., ... Jiménez-Reyes, P. (2017). Mechanical and Metabolic Responses to Traditional and Cluster Set Configurations in the Bench Press Exercise. Journal of Strength and Conditioning Research, (September), 1. https://doi.org/10.1519/JSC.0000000000002301

García-Ramos, A., Nebot, V., Padial, P., Valverde-Esteve, T., Pablos-Monzó, A., \& Feriche, B. (2016). 
INTERNATIONAL JOURNAL OF ACADEMIC RESEARCH IN BUSINESS AND SOCIAL SCIENCES Vol. 9, No. 1, Jan, 2019, E-ISSN: 2222-6990 @ 2019 HRMARS

Effects of short inter-repetition rest periods on power output losses during the half squat exercise. Isokinetics and Exercise Science, 24(4), 323-330. https://doi.org/10.3233/IES-160634

Haff, G. G., Whitley, A., McCoy, L. B., O’Bryant, H. S., Kilgore, J. L., Haff, E. E., ... Stone, M. H. (2003). Effects of different set configurations on barbell velocity and displacement during a clean pull. Journal of Strength and Conditioning Research, 17(1), 95-103. https://doi.org/10.1519/15334287(2003)017<0095:EODSCO>2.0.CO;2

Hansen, K. T., Cronin, J. B., Pickering, S. L., \& Newton, M. J. (2011). Does Cluster Loading Enhance Lower Body Power Development in Preseason Preparation of Elite Rugby Union Players? Journal of Strength and Conditioning Research, 25(8),

2118-2126. https://doi.org/10.1519/JSC.0b013e318220b6a3

Hardee, J. P., Lawrence, M. M., Utter, A. C., Triplett, N. T., Zwetsloot, K. A., \& McBride, J. M. (2012). Effect of inter-repetition rest on ratings of perceived exertion during multiple sets of the power clean. European Journal of Applied Physiology, 112(8), 3141-3147. https://doi.org/10.1007/s00421-011-2300-x

Iglesias-Soler, E., Mayo, X., Río-Rodríguez, D., Carballeira, E., Fariñas, J., \& Fernández-Del-Olmo, M. (2016). Inter-repetition rest training and traditional set configuration produce similar strength gains without cortical adaptations. Journal of Sports Sciences, 34(15), 1473-1484. https://doi.org/10.1080/02640414.2015.1119299

Lawton, T., Cronin, J., Drinkwater, E., Al, E., Lindsell, R., \& Pyne, D. (2004). The effect of continuous repetition training and intra-set rest training on bench press strength and power. Fitness, J Sports Med Phys, 44(June), 361-367.

Lim, J. J. H., \& Barley, C. I. (2016). Complex Training for Power Development : Practical Applications for Program Design. Strength \& Conditioning Journal, 28(6),

33-43. https://doi.org/10.1519/SSC.0000000000000265

Manson, S. A. (2013). Physiological characteristics of elite female soccer players :Influence of age, position and playing status.

Mayo, X., Iglesias-Soler, E., \& Fernández-Del-Olmo, M. (2014). Effects of Set Configuration of Resistance Exercise on Perceived Exertion. Perceptual and Motor Skills, 119(3), 825-837. https://doi.org/10.2466/25.29.PMS.119c30z3

Moreno, S. D., Brown, L. E., Coburn, J. W., \& Judelson, D. A. (2014). Effect of Cluster Sets on Plyometric Jump Power. Journal of Strength and Conditioning Research, 28(9), 2424-2428. https://doi.org/10.1519/JSC.0000000000000585

Morgans, R., Di Michele, R., \& Drust, B. (2018). Soccer Match Play as an Important Component of the Power-Training Stimulus in Premier League Players. International Journal of Sports Physiology and Performance, 10(1), 1-3. https://doi.org/10.1123/ijspp.2016-0412

Oliver, J. M., Jagim, A. R., Sanchez, A. C., Mardock, M. A., Kelly, K. A., Meredith, H. J., ... Kreider, R. B. (2013). Greater Gains in Strength and Power With Intraset Rest Intervals in Hypertrophic Training. Journal of Strength and Conditioning Research, 27(11), 3116-3131. https://doi.org/10.1519/JSC.0b013e3182891672

Roll, F., \& Omer, J. (1987). FOOTBALL: Tulane Football Winter Program. Strength \& Conditioning Journal, 9(6), 34-38. Retrieved from https://journals.lww.com/nscascj/Fulltext/1987/12000/FOOTBALL_Tulane_Football_Winter_Program.4.aspx 
INTERNATIONAL JOURNAL OF ACADEMIC RESEARCH IN BUSINESS AND SOCIAL SCIENCES

Vol. 9, No. 1, Jan, 2019, E-ISSN: 2222-6990 @ 2019 HRMARS

Sáez de Villarreal, E., Requena, B., Izquierdo, M., \& Gonzalez-Badillo, J. J. (2013). Enhancing sprint and strength performance: Combined versus maximal power, traditional heavy-resistance and plyometric training. Journal of Science and Medicine in Sport, 16(2), 146-150. https://doi.org/10.1016/j.jsams.2012.05.007

Sands, W. A., Apostolopoulos, N., Kavanaugh, A. A., \& Stone, M. H. (2016).

Recovery-Adaptation. Strength and Conditioning Journal, 38(6),

10-26. https://doi.org/10.1519/SSC.0000000000000260

Scott, D. J., Ditroilo, M., \& Marshall, P. A. (2017). Complex Training. Journal of Strength and Conditioning Research, 31(10), 2694-2703. https://doi.org/10.1519/JSC.0000000000001722

Talpey, S. W., Young, W. B., \& Saunders, N. (2016). Is nine weeks of complex training effective for improving lower body strength, explosive muscle function, sprint and jumping performance? International Journal of Sports Science \& Coaching, 11(5), 736-745. https://doi.org/10.1177/1747954116667112

Thomas, K., French, D., \& Hayes, P. . (2009). The Effects of Two Plyometric Training Techniques on Muscular Power and Agility in Youth Soccer Players. Journal of Strength and Conditioning Research / National Strength \& Conditioning Association, 00(0), 1-4.

Tredrea, M. S. J. (2017). Applied Complex Training: An Updated Review and Practical Applications. Journal of Australian Strength \& Conditioning, 25(3), 71-85.

Treeraj, A., Kamutsri, T., Lawsirirat, C., \& Intiraporn, C. (2016). Matching Physiological Demand of Competitive Soccer $\backslash r \backslash n$ Matches with Comprehensive Complex Training for $\backslash r \backslash n$ Soccer Players. Journal of Exercise Physiology, 19(6), 94-104.

Tufano, J. J., Brown, L. E., \& Haff, G. G. (2016). Theoretical and Practical Aspects of Different Cluster Set Structures. Journal of Strength and Conditioning Research, 31(3), 848-867. https://doi.org/10.1519/JSC.0000000000001581

Tufano, J. J., Conlon, J. A., Nimphius, S., Brown, L. E., Banyard, H. G., Williamson, B. D., ... Haff, G. G. (2017). Cluster Sets Permit Greater Mechanical Stress Without Decreasing Relative Velocity. International Journal of Sports Physiology and Performance, 12(4), 463-469. https://doi.org/10.1123/ijspp.2015-0738

Tufano, J. J., Conlon, J. A., Nimphius, S., Brown, L. E., Petkovic, A., Frick, J., \& Gregory Haff, G. (2017). Effects of Cluster Sets and Rest-Redistribution on Mechanical Responses to Back Squats in Trained Men. Journal of Human Kinetics, 58(1), 35-43. https://doi.org/10.1515/hukin-20170069

Tufano, J. J., Conlon, J. A., Nimphius, S., Brown, L. E., Seitz, L. B., Williamson, B. D., \& Gregory Haff, G. (2016). Maintenance of velocity and power with cluster sets during high-volume back squats. International Journal of Sports Physiology and Performance, 11(7), 885-892. https://doi.org/10.1123/ijspp.2015-0602

Tufano, J. J., Conlon, J. A., Nimphius, S., Oliver, J. M., Kreutzer, A., \& Haff, G. G. (2017). Different Cluster Sets Result In Similar Metabolic, Endocrine, And Perceptual Responses In Trained Men. Journal of Strength and Conditioning Research, 1. https://doi.org/10.1519/JSC.0000000000001898

Wisløff, U., Castagna, C., Helgerud, J., Jones, R., \& Hoff, J. (2004). Strong correlation of maximal squat strength with sprint performance and vertical jump height in elite soccer players. British Journal 
INTERNATIONAL JOURNAL OF ACADEMIC RESEARCH IN BUSINESS AND SOCIAL SCIENCES Vol. 9, No. 1, Jan, 2019, E-ISSN: 2222-6990 @ 2019 HRMARS

of Sports Medicine, 38(3), 285-8. https://doi.org/10.1136/BJSM.2002.002071 